\title{
Hippocampus abnormalities in at risk mental states for psychosis? \\ A cross-sectional high resolution region of interest magnetic resonance imaging study
}

Author names and affiliations:

Eva Buehlmann ${ }_{1}^{1}$, Gregor E. Berger ${ }^{3}$ Jacqueline Aston ${ }_{2}^{1}$, Ute Gschwandtner ${ }^{1}$, Marlon Pflueger, Stefan J. Borgwardt, Ernst-Wilhelm Radue , Anita Riecher-Rössler

University Hospital Basel, Psychiatric Outpatient Department, Petersgraben 4, $\mathrm{CH}$ 4031 Basel, Switzerland

2 University Hospital Basel, Department of Neuroradiology, Petersgraben 4, CH4053

$\underset{3}{B}$ Basel, Switzerland

Clienia Schloessli Clinic, Department of Research and Education, Oetwil am See, Zuerich, Switzerland

\section{Corresponding author}

Prof. Dr. med. A. Riecher-Rössler, University Hospital Basel, Psychiatric Outpatient Department, Petersgraben 4, CH-4031 Basel, Switzerland phone 061265 5114, fax 061 265 5114, email: ariecher@uhbs.ch

\section{Keywords:}

schizophrenia, hippocampus, Magnetic Resonance Imaging (MRI), first episode psychosis (FEP), at risk mental state (ARMS), ultra-high risk (UHR) 
Hippocampal Abnormalities

\section{Abstract:}

Background: Hippocampal volume (HV) reduction is well documented in schizophrenia. However, it is still unclear whether this change is a pre-existing vulnerability factor, a sign of disease progression, a consequence of environmental factors, such as drug use, antipsychotic medication, or malnutrition. The timing of $\mathrm{HV}$ changes is not well established, but a lack of macrostructural hippocampal brain abnormalities before disease onset would rather support a neuroprogressive illness model.

Aim: To investigate the timing of HV changes in emerging psychosis.

Methods: A cross-sectional MRI study of manually traced HVs in 37 individuals with an At Risk Mental State (ARMS) for Psychosis, 23 individuals with First Episode Psychosis (FEP), and 22 Healthy Controls (HC) was performed. We compared left and right HVs corrected for whole brain volume across groups using analysis of covariance (ANCOVA) with gender as a covariate. 16 of 37 ARMS individuals developed a psychotic disorder during follow up (ARMS-T). The mean duration of follow up in ARMS was 25.1 months. Results: The overall ANCOVA model comparing left HVs across FEP, ARMS and HC indicated a significant general group effect $(p<.05)$ with largest volumes in ARMS and smallest in FEP. ARMS-T subjects had significantly larger left HVs compared to FE but no HV differences compared to HC $(p<0.05)$. Over all groups, we found an asymmetry between the left and right mean HVs and a strong effect of sex.

Discussion: The present study suggests that macrostructural hippocampal abnormalities probably occur in the context of the first psychotic breakdown. 
Hippocampal Abnormalities

\section{INTRODUCTION}

Structural brain abnormalities in schizophrenia have been detected in post mortem studies and in vivo brain imaging studies (Wolf et al, 2008; Kubicki et al, 2007; Whitford et al, 2007; Laywer et al, 2006; Bogerts et al, 1990a,b; Witthaus et al, 2008). However, the extent to which these findings are related to vulnerability for schizophrenia, as opposed to the disease progression, is less certain. The hippocampus as a key region of interest has been investigated in numerous studies at different stages of the disease (Lopez-Garcia et al, 2006; Nelson et al, 1998; Phillips et al, 2002; Steen et al, 2006; Velakoulis et al, 2006) and is among the most robust brain abnormalities found in schizophrenia (Seidmann et al, 2003; Knable et al, 2004). The hippocampus is of particular interest as it is highly interconnected with other brain regions, including the frontal lobe that has also been proposed to be important for schizophrenia (Honea et al, 2005; Hurlemann et al, 2008; Shenton et al, 2001). A meta-analysis found hippocampal volume $(\mathrm{HV})$ reductions of about $4 \%$ in chronic schizophrenia (Nelson et al, 1998) and of about $2.7 \%$ in first-episode schizophrenia (Steen et al, 2006) compared to healthy controls $(\mathrm{HC})$. It seems that HV reductions in first-episode psychosis (FEP) are less extensive than in chronic populations (Bogerts et al, 1990; Hirayasu et al, 1998; Lawrie et al, 1999; Steen et al, 2006; Velakoulis et al, 2006).

Using voxel-based morphometry (VBM) in ARMS individuals a range of gray (Borgwardt et al, 2007a, b; Meisenzahl et al, 2008; Pantelis et al, 2003) and white (Witthaus $\mathrm{H}$ et al, 2008) matter abnormalities across several brain regions could be identified, including temporal lobe encompassing hippocampal structures. In our own VBM study (Borgwardt et al. 2007 a, b) the left parahippocampus and hippocampus in ARMS was smaller compared to controls (at a liberal significance threshold). Within the ARMS group, subjects with later transition to psychosis (ARMS-T) showed more gray matter volume reduction in the parahippocampal gyrus compared to ARMS without later transition 
Hippocampal Abnormalities

(ARMS-NT). The findings are in accordance with longitudinal follow up data from the Melbourne group suggesting that those ARMS individuals who progress towards a psychotic illness have left medial temporal structural changes (Pantelis et al, 2003).

A recent study using manual tracing of the hippocampus across different stages of psychotic disorders from ARMS to FEP to chronic schizophrenia did not find macrostructural hippocampus abnormalities prior to the first psychotic breakdown (Velakoulis et al, 2006). The latter study found that patients with chronic schizophrenia compared to HC had smaller hippocampi bilaterally, and FEP with schizophrenia had only left-sided HV deficits, whereas those with schizophreniform, affective, or other psychoses, as well as ARMS individuals independent of later transition status were not different from HC. This study was in accordance with earlier studies that showed left hippocampal volume reduction in first-episode psychosis (Velakoulis et al, 1999), but not in the baseline MRIs of ARMS individuals who later developed a FEP (Phillips et al, 2002). Interestingly, the latter small study found that left HVs of ARMS subjects who later developed a psychotic disorder were larger than ARMS subjects who did not (but were not significantly different compared to the healthy comparison group). In summary, these VBM and ROI studies suggest that HVs are differentially affected depending on stage and type of psychosis.

The aim of our study was to further explore the timing of hippocampal volume changes in emerging psychosis. Based on our own work (Borgwardt et al. 2007a, b, 2008) and previous structural neuroimaging studies (Pantelis et al, 2003; Phillips et al. 2002; Velakoulis et al 2006) we hypothesized that HVs of FEP patients are smaller compared to individuals with an ARMS, whereas ARMS subjects show smaller HVs compared to HC. Furthermore, we hypothesized that HVs of ARMS individuals with later transition to 
Hippocampal Abnormalities

psychosis are smaller compared to ARMS individuals without later transition to psychosis, as well as compared to HC.

\section{MATERIALS AND METHODS}

\subsection{Study design}

This imaging study was embedded in a naturalistic, prospective study on the prediction of transition to psychosis in individuals with an ARMS, the Basel Early-detection-ofPsychosis (FePsy) study. A more detailed description of the overall study design can be found elsewhere (Riecher-Rössler et al, 2007). The institutional ethics committee of the University of Basel approved all aspects of the study and written informed consent was obtained from each participant.

\subsection{Participants}

Subjects were recruited from a service area covering 200.000 inhabitants in and around Basel, Switzerland, in the framework of the FePsy project (Früherkennung von Psychosen), a multi-domain study on the early detection of psychosis. For screening purposes, we used the Basel Screening Instrument for Psychosis, BSIP (RiecherRössler et al, 2008), a 46-item checklist based on variables which have been shown to be risk factors or early symptoms of psychosis (Riecher-Rössler et al, 2006; RiecherRössler et al, 2007, Riecher-Rössler et al, 2009) such as DSM-III-R-'prodromal' symptoms, social decline, drug abuse, previous psychiatric disorders or genetic liability for psychosis. The severity of (pre-)psychotic phenomena was assessed with the Brief Psychiatric Rating Scale (BPRS), which was used in combination with the BSIP. The BSIP was constructed as a screening checklist to identify those at risk and is followed by 
Hippocampal Abnormalities

a more extensive early detection interview in a next step. To assess the IQ we used the MWT (Lehrl, 1991), an established measure in German-speaking subjects. Experienced psychiatrists who underwent regular training conducted all assessments.

\subsection{Inclusion criteria}

\subsubsection{ARMS group}

The ARMS group was defined using criteria corresponding to the PACE criteria (Yung et al, 1998, McGorry at al, 2002) employed also in previous MRI studies of subjects with an ARMS (Borgwardt et al, 2006, 2007b; Garner et al, 2005; Pantelis et al, 2003; Phillips et al, 2002; Velakoulis et al, 2006). Inclusion thus required one or more of the following: a) "Attenuated" psychotic symptoms, b) brief limited intermittent psychotic symptoms (BLIPS), or c): a first degree relative with a psychotic disorder plus at least two indicators of a clinical change, such as a marked decline in social or occupational functioning. Inclusion because of "attenuated" psychotic symptoms required scores of 2 or 3 on the hallucination item, 3 or 4 on the unusual thought content or suspiciousness items of the BPRS for at least several times a week and persisting for more than 1 week. Inclusion because of BLIPS required scores of 4 or above on the hallucination item, or 5 or above on the unusual thought content, suspiciousness or conceptual disorganization items of the BPRS, with each symptom lasting less than 1 week before resolving spontaneously.

\subsubsection{FEP group}

Assignment to the FEP group was based on the transition criteria for a psychotic episode described by Yung et al (1998) which are shown in table 1. 
Hippocampal Abnormalities

Table 1 here

\subsubsection{HC group}

Healthy controls were recruited from the same geographical area as the other groups through local advertisements. These individuals had no current psychiatric disorder, no history of psychiatric illness, head trauma, neurological illness, serious medical or surgical illness, substance dependency (except for cannabis and nicotine), and no family history of any psychiatric disorder as assessed by an experienced psychiatrist in a detailed clinical interview.

\subsection{Exclusion Criteria}

Exclusion criteria are age below 18 years, insufficient knowledge of German, IQ $<70$, previous psychotic episode treated with major tranquillizers for more than 3 weeks (lifetime), a clearly diagnosed brain disease or substance dependency (except for cannabis dependency), or psychotic symptoms within a clearly diagnosed depressive or borderline personality disorder.

The latter two exclusion criteria are different to the Melbourne ultra-high risk and first episode psychosis criteria that do not exclude subjects with a 'major depression with psychotic features', or Borderline Personality Disorder with psychotic symptoms. We decided to exclude those subjects if the primary diagnosis of major depression or Borderline personality disorder was present prior to the ARMS to focus on a more 
Hippocampal Abnormalities

narrow at risk sample for schizophrenia.

\subsection{Clinical follow-up and transition to psychosis}

All subjects were followed-up regularly and were offered supportive counselling and clinical management. During the first year of follow-up, ARMS individuals were assessed monthly. During the second and third year, all individuals were assessed at least 3monthly and thereafter once a year until transition to frank psychosis or until end of Mai 2007. Transition to psychosis was monitored using criteria described by Yung et al (1998), see table 1. The diagnosis was determined by a diagnostic interview using DSM-IV/ICD-10 research criteria at the time of conversion to frank psychosis, then also assessed at least one year post transition using Operational Criteria (OPCRIT) (McGuffin et al, 1991).

\subsection{Structural MRI}

\subsubsection{Image Acquisition}

Subjects were scanned using a SIEMENS (Erlangen, Germany) MAGNETOM VISION 1.5T scanner at the University Hospital Basel. Head movement was minimised by foam padding and velcro straps across the fore-head and chin. A three-dimensional volumetric spoiled gradient recalled echo sequence generated 176 contiguous, $1 \mathrm{~mm}$ thick sagittal slices. Imaging parameters were: time-to-echo, $4 \mathrm{msec}$; time-to-repetition, $9.7 \mathrm{msec}$; flip angle, 12; matrix size, 200x256; field of view, $25.6 \times 25.6 \mathrm{~cm}$ matrix; voxel dimensions, $1.28 \times 1 \times 1 \mathrm{~mm}$.

2.6.2 Manual segmentation of hippocampus volume 
Hippocampal Abnormalities

Significant clusters were anatomically localised using the atlases of Duvernoy (1998) and Talairach and Tournoux $(1988,1993)$. The regions of interest $(\mathrm{ROI})$ were manually traced by a single tracer (EB) with a mouse-driven cursor using the interactive public domain software program AMIRA, which displays all three planes simultaneously (Kappos et al, 2006). The boundaries of the hippocampus were identified including the subiculum, cornu ammonis (hippocampus proper), and the dentate gyrus. The amygdala was excluded. The regions of interest were defined on the coronal and sagittal slices, and finally checked on the coronal plane again. Anterior segmentation was achieved by tracing on sagittal slices. The hippocampal volume was traced generally following the protocol of Jack et al (1989):

1. Medial: the border between the subiculum and the parahippocampal gyrus

2. Lateral: the temporal horn of the lateral ventricle

3. Inferior: the gray/white matter junction between the subiculum and the white matter in the parahippocampal gyrus

4. Superior: the fimbria was included as the superomedial border of the hippocampus, superolateral gray matter, which was clearly the tail of the caudate, was excluded

5. Posterior, the section where the crura of the fornix are seen in full profile

6. Anterior: the level at which the uncal recess of the temporal horn, or the alveus is visible in the most anterior slice

The intra-rater reliability ranged from $\mathrm{K}=0.962$ (left side) to $\mathrm{K}=0.97$ (right side) using manual segmentation in ten consecutive cases that were measured twice within three weeks. A inter-rater reliability could not be calculated as there was only one tracer. 
Hippocampal Abnormalities

However, previous studies using the same software on data sets comprising over 1000 MRI scans showed a very high inter-rater reliability (Kappos et al, 2006). The researcher who traced the hippocampus was blind to the group at any time of the study. Once the hippocampus has been traced, hippocampal volumes (in $\mathrm{mm} 3$ ) were calculated by computing the number of voxels from each traced image. The average number of traced slices was 26 (SD 4.1 left, 4.4 right) on both sides. Raw volumes were normalized using the following formula for volume correction: Normalized corrected hippocampus volume $(\mathrm{CV})=$ Measured volume $(\mathrm{MV})-$ gradient (measured intracranial volume, ICV - mean intracranial volume of the control group, ICV), (Free et al, 1995).

\subsubsection{Image Processing for Whole Brain Volumes}

The fully automated software SIENAX (Structural Image Evaluation, using Normalisation, of Atrophy in a single-time-point estimation) was used for estimation of the whole brain volumes from a single image, normalised for skull size (Smith et al, 2007). The method has been described elsewhere in detail (www.fmrib.ox.ac.uk/fsl). Briefly, the software first strips non-brain tissue, and then uses the brain and skull images to estimate the scaling between the subject's image and standard space. It then runs tissue segmentation to estimate the volume of brain tissue, and multiplies this by the estimated scaling factor, to reduce head-size-related variability between subjects (Smith et al, 2002).

\subsection{Statistical analysis}

Statistical analyses were performed with the Statistical Package for the Social Sciences, version 15 (SPSS 15.0). Two sets of analysis were performed to test our hypothesis: Analysis 1: ARMS, FEP and HC; Analysis 2: Comparison of ARMS-T, ARMS-NT, FEP and HC. Within each analysis, patient groups were compared with the control group. 


\section{Hippocampal Abnormalities}

Demographic data were compared using Chi-square test and Fisher's exact test for categorical variables; Student's t-tests for psychopathology scores (interval-scaled or continuous variables). Left and right HVs corrected for whole brain volumes were analyzed using one-way analyses of co-variance (ANCOVA) with sex as a covariate. All pair wise mean comparisons used post hoc contrasts to compare patients groups with controls, adjusting for sex. Bonferroni adjustment for multiple testing was applied. Results of statistical tests are given as mean \pm standard deviation (SD). The level of statistical significance was set to $p<0.05$, a trend was considered $p<0.1$. Unadjusted alpha value must not exceed a value of 0.017 in order to reach significance of $p=0.05$.

\section{RESULTS}

\subsection{Sample characteristics}

$70,3 \%$ of ARMS individuals belonged to the prepsychotic group, whereas $18.8 \%$ belonged to the genetic risk group, and $10.9 \%$ had BLIPS in the past. Within the prepsychotic group, $20.1 \%$ also had a genetic risk. ARMS, FEP and HC did not differ significantly with respect to age $\left(\chi^{2}=7.7, \mathrm{df}=4, \mathrm{p}=1.00\right)$, $\operatorname{sex}\left(\chi^{2}=1.5, \mathrm{df}=2, \mathrm{p}=.468\right)$ and handedness $\left(\chi^{2}=3.1, d f=2, p=.208\right)$. Educational level was significantly higher in $\mathrm{HC}$ $\left(\chi^{2}=14.0, d f=4, p=0.007\right)$. Antipsychotic medication was more common in FEP compared to ARMS (Fisher's exact test with $\mathrm{p}=0.022$ ) (table 2).

\section{TABLE 2 ABOUT HERE}


Hippocampal Abnormalities

The mean duration of follow up of the 37 ARMS individuals was 25.1 months (ARMS-T 12.3 months, ARMS-NT 33.1 months). Sixteen of 37 ARMS individuals (43\%) made a transition to psychosis. Ten of the transitions occurred during the first year of follow up, five in the second year and one in the following years. At intake into the FePsy project, subjects who consequently made the transition to psychosis (ARMS-T) did not differ from ARMS-NT in age $(t=1.46, d f=35, P=0.155)$, sex (Fisher's exact test $p=0.500)$, handedness (Fisher's exact test $\mathrm{p}=0.287$ ), education $\left(\mathrm{X}^{2}=2.0, \mathrm{df}=3, \mathrm{P}=0.580\right)$, mean BPRS global score $(t=1.63, d f=35, P=0.113$; Mean SANS: $t=1.66, d f=35, P=0.106)$ and exposure to antipsychotic medications (Fisher's exact test $\mathrm{p}=1.00$ ) (table 3 ).

TABLE 3 ABOUT HERE

\subsection{Whole brain volumes, sex and age}

Whole brain volume corrected for age $(F=0.3, d f=2, P=0.708)$ did not differ across groups. However, women had smaller whole brain volumes in each group (HC: $t=-4.025$, $d f=20, p<0.010 ;$ ARMS: $t=-4.445, d f=35, p<0.010 ; F E P: t=-2.031, d f=21, p=0.055)$. Sex was therefore included as a covariate in all subsequent ANCOVAs.

\subsection{Hippocampal volumes}

Over all diagnostic groups, we found a significant asymmetry between the left and right mean $\mathrm{HVs}(\mathrm{t}=-14.548, \mathrm{df}=81, \mathrm{p}<.01)$ and a significant effect of sex (left $\mathrm{t}=4.4, \mathrm{df}=80$, $\mathrm{p}<.001$; right $\mathrm{t}=3.5, \mathrm{df}=80, \mathrm{p}=.001)$. Therefore, all $\mathrm{HV}$ group comparisons were analysed for each side separately corrected for whole brain volume and with sex as a covariate. 
Hippocampal Abnormalities

Analysis 1 (comparison of ARMS total, FEP and $\mathrm{HC}$ ) revealed a significant group effect for the adjusted left $H V s\left(F_{2,78}=3.5 ; P=.035\right)$. The adjusted right $H V$ did not differ $\left(F_{2,78}=0.5, P=.624\right)$. The respective power found in these comparisons was $1-\beta=0.572$ for the left, and $1-\beta=0.120$ for the right side. Mean left $H V$ s revealed a $6.9 \%$ volume reduction in FEP (2993mm3) compared to ARMS (3155mm3) using the Welch two sample t-test $(t=2.032 ; d f=52.34 ; P=0.047)$, however probably as a consequence of the relatively small sample size and insufficient power, significance was lost $(P=0.14)$ after controlling for multiple comparison using Bonferroni adjustment. The right mean HV did not differ between the FEP and ARMS $(t=0.861, d f=58, p \approx 1.00)$. Mean left HV in FEP was $4.5 \%$ smaller compared to $\mathrm{HC}$ without reaching level of significance $(\mathrm{t}=-1.191$, $d f=41.063, p=0.241)$. The right hippocampus did not differ between these groups $(t=-$ $0.149, \mathrm{df}=78, \mathrm{p}=0.882$ ). Neither left nor right hippocampal volumes of the ARMS group did differ from HC (Welch Two Sample t-test, left: $+2.4 \%, t=1.037, d f=56.424, p=.304$; right: $t=0.35, d f=57, p=.727)$.

Analysis 2 (comparison of ARMS-T, ARMS-NT, FEP and HC) revealed a trend for group effects for the adjusted left $\mathrm{HVs}(\mathrm{F}=2.4, \mathrm{df}=3,77, \mathrm{p}=0.074$, sex effect: $F=17.7, \mathrm{df}=1,77$, $\mathrm{p}<0.001)$, whereas no significant difference was found for the right mean $\mathrm{HV}(\mathrm{F}=0.3$, $\mathrm{df}=3,77, \mathrm{p}=.815$, sex effect: $F=11.1, \mathrm{df}=1.77, \mathrm{p}<0.01)$. Interestingly, the power on the left side was moderate, whereas on the right low (left: $1-\beta=0.584$; right: $1-\beta=0.119$ ). Mean left HVs of ARMS-T were significantly larger compared to FE ( $t=2,25, p=0.027)$, wheras the right HV's did not differ between these groups $(t=0,70, p=0,488)$. Mean HVs of ARMS-T and ARMS-NT did not differ significantly (left $\mathrm{t}=0.33, \mathrm{p}=0.744$; right $\mathrm{t}=0.046$, $\mathrm{p}=0.964$ ). Mean HVs of ARMS-T also did not differ compared to HC (left $t=1.288$, $p=0.202$; right $t=0.560, p=0.577$ ). 
Hippocampal Abnormalities

\section{DISCUSSION}

The current cross-sectional MRI study compared manually traced HVs between ARMS, FEP and $\mathrm{HC}$ adjusted for sex and whole brain volumes. Whereas the right HVs did not differ between the groups, we found a significant difference in left HVs between ARMS, FEP and $\mathrm{HC}(\mathrm{P}=0.035)$, with a left $\mathrm{HV}$ reduction of $6.9 \%$ in FEP compared to ARMS, and a left $\mathrm{HVs}$ reduction of $4.5 \%$ in FEP compared to $\mathrm{HC}$. We also showed that mean left HVs of ARMS subjects with later transition to psychosis (ARMS-T) were significantly larger compared to FE, whereas the right HV's did not differ between these groups $(t=0,70, p=0,488)$. Contrary to our expectation, we were not able to demonstrate left or right HV differences between ARMS and HC, nor within the ARMS group (ARMS-T vs. ARMS-NT).

Our findings in patients are consistent with previous neuroimaging reports from the same sample (Borgwardt et al, 2007a, 2008; Haller et al., 2009) and similar to other ARMS samples (Velakoulis et al, 2006; Meisenzahl et al, 2008), as well as longitudinal MRI studies using voxel-based morphometry methods, where progressive volumetric reductions in hippocampal and parahippocampal regions were found in those ARMS subjects that made a transition to psychosis (Pantelis et al, 2003). Furthermore, also the finding that non-converters (ARMS-NT) compared to converters (ARMS-T) did not differ in left or right HVs is well in line with previous VBM studies of ARMS (Borgwardt et al, 2007a; Meisenzahl et al, 2008, Pantelis et al 2003). Both converters and non-converters showed no difference in HV compared to healthy controls. This finding also replicates a previous ROI-study in a larger ARMS sample (Velakoulis et al, 2006). 
Hippocampal Abnormalities

Finally our finding of a left laterality of hippocampus abnormality is in line with some previous studies (Velakoulis et al, 1999, 2006), but not all (Hurlemann et al. 2008). We believe that there are several reasons for the inconsistent results. Previous studies which found an early left sided pathology usually have a younger cohort, and a more phenomenologically defined ascertainment strategy (Velakoulis et al, 1999, 2006), whereas studies with a bilateral HV reduction used different ascertainment strategies including older and potentially more progressed ARMS subjects with cognitive impairment, related to the biological substrate.

The hippocampus is a region of high plasticity which depends on various genetic and environmental influences (Cruther and Collins, 1982; Knable et al, 2004) including illness stage and treatment (Berger et al, 2003). The hippocampal plasticity may also explain why, left HV in ARMS was slightly bigger than in HC (albeit not significantly) and significantly bigger than in FEP. The latter is in line with an earlier study by Phillips et al (2002) and might precede the onset of psychosis. The underlying substrate for such a 'swelling' prior to the actual conversion to psychosis could be an increased apoptotic activity involving a transient controlled inflammatory response while removing apoptotic cells, or cell parts (axons and dendrites) (Berger et al, 2003; Lieberman et al, 2007). If true, this may imply that new benign neuroprotective treatment strategies may be especially effective in this late phase of prodrome and be able to modulate underlying neurobiological processes and potentially delay or even prevent the onset of psychosis (Berger et al, 2007)

Our study may not be fully comparable to other structural MRI studies because different research groups have used slightly different ways of defining their high risk (Fusar-Poli P et al, 2008; Yung et al, 2008) and first episode psychosis (McGorry et al, 2004; Schimmelmann et al 2005) cohorts, used different ascertainment strategies, different 
Hippocampal Abnormalities

anatomic boundaries of the hippocampus (with or without amygdala) as well as applied different techniques to measure HV (i.e. manual vs. automated methods). MRI scanner technology has also changed rapidly over the past decades, and different studies may therefore hardly be comparable (e.g. different slice thickness in older studies). The methods and extent of detailed information how ROls were defined varies across studies, again suggesting that the information may not be easily comparable. Furthermore, there is a large difference in potential confounding factors across studies (i.e. sex, duration of illness, age of onset, medication, drug use, parental and socioeconomic status), which makes a direct comparison across studies difficult. Another likely reason for the inconclusiveness of previous studies is that pathological changes of brain structure in schizophrenia might not be limited to one or a few clearly defined brain regions. There is considerable evidence that the pathological changes in patients with schizophrenia may be at the level of spatially distributed networks that include multiple, densely interconnected cortical and subcortical regions (Weinberger et al, 1992; Wright et al, 2000, Witthaus $\mathrm{H}$. et al, 2008) highlighting that schizophrenia may be rather a whole brain disorder and interpretation of changes in one single region can potentially be misleading.

Finally, it is unlikely that these findings are specific to schizophrenia (Geuze et al, 2005). Smaller HV have also been reported in other neurological (Alzheimer's disease: Teipel et al, 2003; Parkinson's disease: Brueck et al 2004; Epilepsy: Marsh et al 2001; Huntington's disease: Rosas et al 2003, medical cardiac arrest: Fujioka et al 2000; Cushing disease: Starkman et al 1999; amnesia: Isaacs et al 2003; Herpes simplex: Colchester et al 2001) and psychiatric (Major Depression: Bremner et al 2000; Bipolar disorder: Bearden et al, 2008) disorders.

A major limitation of our study is the relatively small sample size with the consequence that we may be unable to detect small group differences because of limited statistical 
Hippocampal Abnormalities

power. For analysis 1, post hoc test applying the Bonferroni assumption for multiple testing was not able to uphold the significance. Since the power of the group effects is low, a correction for multiple testing is probably disproportionately conservative and the likelihood of a type II error ('false negative') applying such post hoc tests is quite high. Furthermore, the cross-sectional nature of the data limits interpretation as HV differences may be an epiphenomenom of another underlying disease pathology such as a dysregulation in the HPA axis (Phillips et al, 2006). Finally, our FEP and ARMS sample was not completely drug naive, bearing the risk that drug effects might have masked some of the volumetric abnormalities (Lieberman et al, 2005). However, $89 \%$ of the ARMS subjects were naive to these medications and the few ARMS subjects who received antipsychotic medications were treated only for behavioral control with very low doses and over a very short time period ( $<3$ weeks). Therefore, if a medication effect was present, it was mainly relevant for the FEP group and more likely to protect the hippocampus than the opposite (Liebermann et al, 2005).

In conclusion, our study provides further evidence that macrostructural hippocampal abnormalities probably occur in the context of the first psychotic breakdown. With regard to the hippocampus, it suggests a biphasic course of events which encompasses a primary swelling proximal to psychosis onset and a secondary volumetric diminution, supporting a rather neuroprogressive model of psychotic disorders. Future studies investigating hippocampal abnormalities should use longitudinal approaches from ARMS onwards with larger sample sizes and neuroendocrinological and cognitive measurement to shed light on the underlying neuropathology of hippocampus abnormalities in emerging psychotic disorders. 
Hippocampal Abnormalities

\section{REFERENCES}

Bearden CE, Soares JC, Klunder AD, Nicoletti M, Dierschke N, Hayashi KM, Narr KL, Brambilla P, Sassi RB, Axelson D, Ryan N, Birmaher B and Thompson PM. Three-dimensional mapping of hippocampal anatomy in adolescents with bipolar disorder. J Am Acad Child Adolesc Psychiatry 2008; 47:515-525.

Berger GE, Wood S, McGorry PD. Incipient neurovulnerability and neuroprotection in early psychosis. Psychopharmacol Bull 2003; 37(2):79-101.

Berger GE, Dell'Olio M, Amminger P, Cornblatt B, Phillips L, Yung A, Yan Y, Berk M, McGorry P. Neuroprotection in emerging psychotic disorders. Early Intervention in Psychiatry 2007; 1(2), 114-127.

Bogerts B, Ashtari M, Degreef G, Alvir JM, Bilder RM and Lieberman JA. (1990a) Reduced temporal limbic structure volumes on magnetic resonance images in first episode schizophrenia. Psychiatry Res 1990; 35(1):1-13.

Bogerts B, Falkai P, Haupts M, Greve B, Ernst S, Tapernon-Franz U and Heinzmann U. (1990b) Post-mortem volume measurements of limbic system and basal ganglia structures in chronic schizophrenics. Initial results from a new brain collection. Schizophr Res 1990; 3:295-301.

Borgwardt SJ, Rad , EW, Goetz K, Aston J, Drewe M, Gschwandtner U, Haller S, Pflueger M, Stieglitz RD, McGuire PK, Riecher-R^ssler A. Radiological findings in individuals at high risk of psychosis. J Neurol Neurosurg Psychiatry 2006; 77(2):229-33. 
Hippocampal Abnormalities

Borgwardt SJ, Riecher-Rössler A, Dazzan P, Chitnis X, Aston J, Drewe M, Gschwandtner U, Haller S, Pfl sger M, Rechsteiner E, Semenin V, Stieglitz RD, $\operatorname{Rad}_{\lrcorner}$EW, McGuire PK. (2007a) Regional gray matter abnormalities in the At Risk Mental State. Biological Psychiatry 2007; 15 (61):1148-56.

Borgwardt SJ, McGuire PK, Aston J, Berger G, Dazzan P, Gschwandtner U, Pflueger M, Rad, EW, Riecher-Rössler A. (2007b) Structural brain abnormlities in individuals with an At Risk Mental State who later develop psychosis. British Journal of Psychiatry 2007; 191(51): 69-75.

Borgwardt SJ, McGuire PK, Aston J, Gschwandtner U, Pfl ger MO, Stieglitz R, Radue „E and Riecher-Rössler A. Reductions in frontal, temporal and parietal volume associated with the onset of psychosis. Schizophr Res 2008; 106(2-3):108-114.

Bremner JD, Narayan M, Anderson ER, Staib LH, Miller HL and Charney DS. Hippocampal volume reduction in major depression. Am J Psychiatry 2000; 157: $115-118$.

Brueck A, Kurki T, Kaasinen V, Vahlberg T and Rinne JO. Hippocampal and prefrontal atrophy in patients with early non-demented Parkinson's disease is related to cognitive impairment. J Neurol Neurosurg Psychiatry 2004; 75:1467-1469.

Byrne M, Hodges A, Grant E, Owens DC and Johnstone EC. Neuropsychological assessment of young people at high genetic risk for developing schizophrenia compared with controls: Preliminary findings of the Edinburgh High Risk Study (EHRS). Psychological Medicine,1999 29: 1161-1173. 
Hippocampal Abnormalities

Colchester A, Kingsley D, Lasserson D, Kendall B, Bello F, Rush C, Stevens TG, Goodman G, Heilpern G, Stanhope N and Kopelman MD. Structural MRI volumetric analysis in patients with organic amnesia, 1: methods and comparative findings across diagnostic groups. J Neurol Neurosurg Psychiatry $2001 ; 71: 13-22$.

Crutcher KA, Collins F. In vitro Evidence for two distinct hippocampal growth factors: basis of neuronal plasticity? Science 1982 2;217(4554):67-8.

Duvernoy HM. The Human Hippocampus: An Atlas of Applied Anatomy. Munich: Bergmann JF, 1998.

Free SL, Bergin PS, Fish DR, Cook MJ, Shorvon SD and Stevens JM. Methods for normalization of hippocampal volumes measured with MR. AJNR Am J Neuroradiol 1995; 16:637-643.

Fujioka M, Nishio K, Miyamoto S, Hiramatsu KI, Sakaki T, Okuchi K, Taoka T and Fujioka S. Hippocampal damage in the human brain after cardiac arrest. Cerebrovasc Dis 2000; 10:2-7.

Fusar-Poli P, Borgwardt S, Valmaggia L. Heterogeneity in the assessment of the at-risk mental state for psychosis. Psychiatr Serv 2008;59(7):813.

Garner B, Pariante CM, Wood SJ, Velakoulis D, Phillips L, Soulsby B, Brewer WJ, Smith DJ, Dazzan P, Berger GE, Yung AR, van den Buuse M, Murray R, McGorry PD, Pantelis C. Pituitary volume predicts future transition to psychosis in individuals at ultra-high risk of developing psychosis. Biol Psychiatry 2005; 58(5):417-23.

Geuze E, Vermetten E, and Bremner JD. Mr-based in vivo hippocampal volumetrics: 2. findings in neuropsychiatric disorders. Mol Psychiatry 2005; 10(2):160-184. 
Hippocampal Abnormalities

Giuliani NR, Calhoun VD, Pearlson GD, Francis A, Buchanan RW. Voxel-based morphometry versus region of interest: a comparison of two methods for analyzing gray matter differences in schizophrenia. Schizophr Res 2005; 74(23):135-47.

Hirayasu Y, Shenton ME, Salisbury DF, Dickey CC, Fischer IA, Mazzoni P, Kisler T, Arakaki H, Kwon JS, Anderson JE, Yurgelun TD, Tohen M, and McCarley RW. Lower left temporal lobe mri volumes in patients with firstepisode schizophrenia compared with psychotic patients with first-episode affective disorder and normal subjects. Am J Psychiatry 1998, 155(10):1384- 1391.

Haller S, Borgwardt SJ, Schindler C, Aston J, Radue EW, Riecher-R^ssler A. Can cortical thickness asymmetry and analysis contribute to detection of at-risk mental state and first-episode psychosis? - a pilot study. Radiology 2009, 250 (1):212-21.

Honea R and Crow TJ and Passingham D and Mackay CE. Regional deficits in brain volume in schizophrenia: a meta-analysis of voxel-based morphometry studies. Am J Psychiatry 2005, 162:2233-2245.

Hurlemann R, Jessen F, Wagner M, Frommann I, Ruhrmann S, Brockhaus A, Picker H, Scheef L, Block W, Schild HH, Moller-Hartmann W, Krug B, Falkai P, Klosterkotter J, Maier W. Interrelated neuropsychological and anatomical evidence of hippocampal pathology in the at-risk mental state. Psychol Med 2008;38:843-51. 
Hippocampal Abnormalities

Isaacs EB, Vargha-Khadem F, Watkins KE, Lucas A, Mishkin M and Gadian DG. Developmental amnesia and its relationship to degree of hippocampal atrophy. Proc Natl Acad Sci U S A 2003; 100:13060-13063.

Jack CR, Twomey CK, Zinsmeister AR, Sharbrough FW, Petersen RC and Cascino GD. Anterior temporal lobes and hippocampal formations: normative volumetric measurements from MR images in young adults. Radiology 1989; 172: 549-554.

Knable MB, Barci BM, Webster MJ, Meador-Woodruff J, Torrey EF; Stanley Neuropathology Consortium. Molecular abnormalities of the hippocampus in severe psychiatric illness: post mortem findings from the Stanley Neuropathology Consortium. Mol Psychiatry 2004, 9(6):609-20, 544.

Kappos L, Antel J, Comi G, Montalban X, O'Connor P, Polman CH, Haas T, Korn AA, Karlsson G, Rad, EW and Group F. T. Y. D. S. Oral fingolimod (FTY720) for relapsing multiple sclerosis. N Engl J Med 2006, 355: 1124-1140.

Kubicki M, McCarley R, Westin C, Park H, Maier S, Kikinis R, Jolesz FA and Shenton ME. A review of diffusion tensor imaging studies in schizophrenia. J Psychiatr Res 2007; 41: 15-30.

Lawrie SM, Whalley HC, Abukmeil SS, Kestelman JN, Miller P, Best JJ, Owens DG, Johnstone EC. Temporal lobe volume changes in people at high risk of schizophrenia with psychotic symptoms. Br J Psychiatry. 2002;181:138-43.

Lawrie SM, Whalley H., Kestelman JN, Abukmeil SS, Byrne M, Hodges, Rimmington JE, Best JJ, Owens DG, and Johnstone EC. Magnetic resonance imaging of brain in people at high risk of developing schizophrenia. Lancet 1999; 353(9146):30-33. 
Hippocampal Abnormalities

Laywer G, Nyman H, Agartz I, Arnborg S, J^nsson EG, Sedvall GC and Hall H. Morphological correlates to cognitive dysfunction in schizophrenia as studied with Bayesian regression. BMC Psychiatry 2006; 6: 31.

Lehrl S. Manual zum MWT-B. 3. sberarbeitete Auflage. Balingen: Perimed-spitta, 1991.

Lieberman JA, Tollefson GD, Charles C, Zipursky R, Sharma T, Kahn RS, Keefe RS, Green Al, Gur RE, McEvoy J, Perkins D, Hamer RM, Gu H, Tohen M and Group H. G. D. H. S. Antipsychotic drug effects on brain morphology in first-episode psychosis. Arch Gen Psychiatry 2005; 62:361-370.

Lieberman JA, Perkins DO, Jarskog LF. Neuroprotection: a therapeutic strategy to prevent deterioration associated with schizophrenia. CNS Spectr 2007;12(3 Suppl 4):1-13.

Lopez-Garcia P, Aizenstein HJ, Snitz BE, Walter RP and Carter CS. Automated ROIbased brain parcellation analysis of frontal and temporal brain volumes in schizophrenia. Psychiatry Res 2006; 147: 153-161.

Marsh L, Sullivan EV, Morrell M, Lim KO and Pfefferbaum A. Structural brain abnormalities in patients with schizophrenia, epilepsy, and epilepsy with chronic interictal psychosis. Psychiatry Res 2001; 108:1-15.

McGorry PD. The influence of illness duration on syndrome clarity and stability in functional psychosis: does the diagnosis emerge and stabilise with time? Aust $\mathrm{N}$ Z J Psychiatry 1994; 28(4):607-19. 
Hippocampal Abnormalities

McGuffin P, Farmer A, and Harvey I. A polydiagnostic application of operational criteria in studies of psychotic illness, development and reliability of the opcrit system. Arch Gen Psychiatry 1991; 48(8):764-770.

Meisenzahl EM, Koutsouleris N, Gaser C, Bottlender R, Schmitt GJ, McGuire P, Decker P, Burgermeister B, Born C, Reiser M, M^ller HJ. Structural brain alterations in subjects at high-risk of psychosis: A voxel-based morphometric study. Schizophr Res 2008;102(1-3):150-62.

Nelson MD, Saykin AJ, Flashman LA, and Riordan HJ. Hippocampal volume reduction in schizophrenia as assessed by magnetic resonance imaging: a meta-analytic study. Arch Gen Psychiatry 1998; 55(5):433-440.

Pantelis C, Velakoulis D, McGorry PD, Wood SJ, Suckling J, Phillips LJ, Yung AR, Bullmore ET, Brewer W, Soulsby B, Desmond P, and McGuire PK. Neuroanatomical abnormalities before and after onset of psychosis: a crosssectional and longitudinal mri comparison. Lancet 2003; 361(9354):281288.

Phillips LJ, Velakoulis D, Pantelis C, Wood S, Yuen HP, Yung AR, Desmond P, Brewer W, and McGorry PD. Non-reduction in hippocampal volume is associated with higher risk of psychosis. Schizophr Res 2002; 58(23):145-158.

Phillips, L. J., McGorry, P. D., Garner, B., Thompson, K. N., Pantelis, C., Wood, S. J., Berger, G. 2006. Stress, the hippocampus and the hypothalamic-pituitary-adrenal axis: implications for the development of psychotic disorders. Aust N Z J Psychiatry, 40(9), 725-741. 
Hippocampal Abnormalities

Riecher-Rössler A, Gschwandtner U, Borgwardt S, Aston J, Pflueger M, and Rössler W. Early detection and treatment of schizophrenia: how early? Acta Psychiatr Scand Suppl 2006; 429:73-80.

Riecher-Rössler A, Gschwandtner U, Aston J, Borgwardt S, Drewe M, Fuhr P, Pflueger M, Rad, W, Schindler Ch and Stieglitz R-D. The basel early detection-ofpsychosis (fepsy)-study : design and preliminary results. Acta Psychiatr Scand 2007; 115(2):114-125.

Riecher-Rössler A, Aston J, Ventura J, Merlo M, Borgwardt S, Gschwandtner U, Stieglitz RD: Das Basel Screening Instrument für Psychosen (BSIP), Fortschr Neurol Psychiatr 2008; 76:207-216.

Riecher-Rössler A, Pflüger MO, Aston J, Borgwardt SJ, Brewer WJ, Gschwandtner U, Stieglitz RD: The efficacy of Using Cognitive Status in Predicting Psychosis: A 7year follow-up, Biological Psychiatry 2009; (doi:10.1016/j.biopsych.2009.07.020)

Rosas HD, Koroshetz WJ, Chen YI, Skeuse C, Vangel M, Cudkowicz ME, Caplan K, Marek K, Seidman LJ, Makris N, Jenkins BG and Goldstein JM. Evidence for more widespread cerebral pathology in early HD: an MRI-based morphometric analysis. Neurology 2003; 60:1615-1620.

Schimmelmann BG, Conus P, Edwards J, McGorry PD, Lambert M. Diagnostic stability 18 months after treatment initiation for first-episode psychosis. J Clin Psychiatry. 2005; 66(10):1239-46.

Seidman LJ, Pantelis C, Keshavan MS, Faraone SV, Goldstein JM, Horton NJ, Makris N, Falkai P, Caviness VS, Tsuang MT. A review and new report of medial temporal lobe dysfunction as a vulnerability indicator for schizophrenia: a 
Hippocampal Abnormalities

magnetic resonance imaging morphometric family study of the parahippocampal gyrus. Schizophr Bull. 2003; 29(4):803-30.

Shenton ME, Dickey CC, Frumin M., and McCarley RW. A review of mri findings in schizophrenia. Schizophr Res 2001; 49(1-2):1-52.

Smith SM, Zhang Y, Jenkinson M, Chen J, Matthews PM, Federico A and Stefano ND. Accurate, robust, and automated longitudinal and crosssectional brain change analysis. Neuroimage 2002; 17:479-489.

Smith SM, Jenkinson M, Woolrich MW, Beckmann CF, Behrens TEJ, Johansen-Berg H, Bannister PR, De Luca M, Drobnjak I, Flitney DE, Niazy R, Saunders J, Vickers J, Zhang Y, De Stefano N, Brady JM, and Matthews PM. Advances in functional and structural MR image analysis and implementation as FSL. Neurolmage 2004, 23(S1):208-219.

Smith SM, Rao A, Stefano ND, Jenkinson M, Schott JM, Matthews PM and Fox NC. Longitudinal and cross-sectional analysis of atrophy in Alzheimer's disease: cross-validation of BSI, SIENA and SIENAX. Neuroimage 2007; 36:1200-1206.

Spencer MD, William T, Moorhead J, McIntosh AM, Stanfield AC, Muir WJ, Hoare P, Owens DG, Lawrie SM and Johnstone EC. Grey matter correlates of early psychotic symptoms in adolescents at enhanced risk of psychosis: A voxel-based study. Neurolmage 2007; 35(3):1181-1191.

Starkman MN, Giordani B, Gebarski SS, Berent S, Schork MA and Schteingart DE. Decrease in cortisol reverses human hippocampal atrophy following treatment of Cushing's disease. Biol Psychiatry 1999; 46:1595-1602. 
Hippocampal Abnormalities

Steen RG, Mull C, McClure R, Hamer RM and Lieberman JA. Brain volume in firstepisode schizophrenia: Systematic review and meta-analysis of magnetic resonance imaging studies. Br J Psychiatry 2006; 188(6):510-518.

Teipel SJ, Bayer W, Alexander GE, Bokde ALW, Zebuhr Y, Teichberg D, M Mller-Spahn F, Schapiro MB, M^ller H, Rapoport SI and Hampel H. Regional pattern of hippocampus and corpus callosum atrophy in Alzheimer's disease in relation to dementia severity: evidence for early neocortical degeneration. Neurobiol Aging 2003; 24:85-94.

Talairach J, Tournoux P. Referentially Oriented Cerebral MRI Anatomy. Stuttgart: Thieme, 1993.

Talairach J, Tournoux P. Co-Planar Stereotaxic Atlas of the Human Brain. Stuttgart: Thieme, 1988.

Velakoulis D, Wood SJ, Wong MTH, McGorry MD, Yung A, Phillips L, Smith De, Brewer W, Proffitt T, Desmond P, and Pantelis C. Hippocampal and amygdala volumes according to psychosis stage and diagnosis: a magnetic resonance imaging study of chronic schizophrenia, first-episode psychosis, and ultra-high-risk individuals. Arch Gen Psychiatry 2006; 63(2):139-149.

Weinberger DR, Berman KF, Suddath R, and Torrey EF. Evidence of dysfunction of a prefrontal-limbic network in schizophrenia: a magnetic resonance imaging and regional cerebral blood flow study of discordant monozygotic twins. Am J Psychiatry 1992; 149(7):890-897.

Whitford TJ, Grieve SM, Farrow TFD, Gomes L, Brennan J, Harris AWF, Gordon E and Williams LM. Volumetric white matter abnormalities in firstepisode schizophrenia: 
Hippocampal Abnormalities

a longitudinal, tensor-based morphometry study. Am J Psychiatry 2007; 164:1082-1089.

Witthaus H, Brüne M, Kaufmann C, Bohner G, Özgürdal S, Gudlowski Y, Heinz A, Klingebiel R, Juckel $\mathrm{G}$. White matter abnormalities in subjects at ultra high-risk for schizophrenia and first-episode schizophrenic patients. Schizophr Res 2008; 102:141-9.

Wolf $\mathrm{RC}, \mathrm{H}^{\wedge}$ se A, Frasch $\mathrm{K}$, Walter $\mathrm{H}$ and Vasic $\mathrm{N}$. Volumetric abnormalities associated with cognitive deficits in patients with schizophrenia. Eur Psychiatry 2008; 23(8):541-8.

Wright C, Rabe-Hesketh S, Woodruff PW, David AS, Murray RM and Bullmore ET. Meta-analysis of regional brain volumes in schizophrenia. Am J Psychiatry 2000; 157(1):16-25.

Yung AR, Phillips LJ, McGorry PD, McFarlane CA, Francey S, Harrigan S, Patton GC, and Jackson HJ. Prediction of psychosis. a step towards indicated prevention of schizophrenia. Br J Psychiatry Suppl 1998; 172(33):14-20.

Yung AR, Nelson B, Stanford C, Simmons MB, Cosgrave EM, Killackey E, Phillips LJ, Bechdolf A, Buckby J, McGorry PD. Validation of "prodromal" criteria to detect individuals at ultra high risk of psychosis: 2 year follow-up. Schizophr Res 2008;105(1-3):10-7. 
Hippocampal Abnormalities

\section{Table 1}

\section{Transition criteria}

At least one of the following symptoms:

i. Suspiciousness (BPRS $\geq 5$ ): subject says others are maliciously talking about him/her, have negative intentions or may induce harm (incidents more than once a week OR partly delusional conviction).

ii. Unusual thought content (BPRS $\geq 5$ ): full delusion(s) with some preoccupation OR some areas of functioning disrupted (not only ideas of reference/persecution, unusual beliefs or bizarre ideas without fixed delusional conviction)

iii. Hallucinations (BPRS $\geq 4$ ): occasional hallucinations $O R$ visual illusions $>2 /$ week or with functional impairment (not only hearing of own name, non-verbal acoustic or formless visual hallucinations/illusions).

iv. Conceptual disorganization (BPRS $\geq 5$ ): speech difficult to understand due to circumstantiality, tangentiality, neologisms, blockings or topic shifts (most of the time OR three to five instances of incoherent phrases).

Symptoms at least several times a week.

Change in mental state lasting $>1$ week. 
Hippocampal Abnormalities

Table 2 Demographic and clinical characteristics

\begin{tabular}{|c|c|c|c|c|}
\hline & $\begin{array}{l}\text { ARMS } \\
(n=37)\end{array}$ & $\begin{array}{l}\text { FEP } \\
(n=23)\end{array}$ & $\begin{array}{l}\mathrm{HC} \\
(\mathrm{n}=22)\end{array}$ & $p$ \\
\hline $\begin{array}{l}\text { Age at baseline (mean } \\
\text { years, SD) }\end{array}$ & $24.7(5.6)$ & $26.78(6.5)$ & $23.0(4.3)$ & $\mathrm{ns}^{1 / 3)}$ \\
\hline Sex (male) & 22 (59\%) & $17(74 \%)$ & $13(59 \%)$ & $n^{4)}$ \\
\hline Handedness (mixed or left) & $4(17 \%)$ & $5(22 \%)$ & $6(29 \%)$ & $n^{4)}$ \\
\hline Educational level & & & & $<0.05^{4)}$ \\
\hline$<9$ yrs & $11(30 \%)$ & $12(52 \%)$ & $2(9 \%)$ & \\
\hline $9-11$ yrs & $14(38 \%)$ & $8(34 \%)$ & 7 (32\%) & \\
\hline $12-13$ yrs & $8(22 \%)$ & $1(4 \%)$ & $10(46 \%)$ & \\
\hline$>13$ yrs & $4(11 \%)$ & $2(9 \%)$ & $3(14 \%)$ & \\
\hline $\begin{array}{l}\text { Individuals with a first } \\
\text { degree relative with } \\
\text { schizophrenia }\end{array}$ & 5 (14\%) & $4(17 \%)$ & & $\mathrm{ns}^{4)}$ \\
\hline $\begin{array}{l}\text { Mean BPRS global score at } \\
\text { intake (SD) }\end{array}$ & $39.2(9.0)$ & $52.7(13.6)$ & na & $<0.001^{3)}$ \\
\hline Mean SANS at intake (SD) & $8.0(5.0)$ & $10.0(5.3)$ & na & $n^{3)}$ \\
\hline Patients with antipsychotics & $4(11 \%)$ & $9(39 \%)$ & na & $<0.05^{5)}$ \\
\hline $\begin{array}{l}\text { Duration of Illness (mean } \\
\text { monthes, SD) }\end{array}$ & $44.1(46.0)$ & $54.9(74.1)$ & na & $\mathrm{ns}^{3)}$ \\
\hline \multicolumn{5}{|l|}{$\begin{array}{l}\text { 1) not significant } \\
\text { 2) not applicable } \\
\text { 3) ANOVA } \\
\text { 4) } \chi^{2} \text {-test } \\
\text { 5) Fisher's exact test }\end{array}$} \\
\hline
\end{tabular}


Hippocampal Abnormalities

Table 3 Demographic and clinical characteristics

\begin{tabular}{|c|c|c|c|}
\hline & $\begin{array}{l}\text { ARMS-T } \\
(n=16)\end{array}$ & $\begin{array}{c}\text { ARMS-NT } \\
(n=21)\end{array}$ & $p$ \\
\hline $\begin{array}{l}\text { Age at baseline (mean } \\
\text { years, SD) }\end{array}$ & 26.44 (6.5) & $23.4(6.0)$ & $\mathrm{ns}^{1)}$ \\
\hline Sex (male) & 11 (69\%) & 11 (52\%) & $n^{2)}$ \\
\hline $\begin{array}{l}\text { Handedness (mixed or } \\
\text { left) }\end{array}$ & 3 (19\%) & $1(5 \%)$ & $n^{2)}$ \\
\hline & & & $\mathrm{ns}^{3)}$ \\
\hline$<9$ yrs & & & \\
\hline $9-11$ yrs & $6(38 \%)$ & $8(39 \%)$ & \\
\hline $12-13$ yrs & $5(31 \%)$ & $3(13 \%)$ & \\
\hline$>13$ yrs & $1(6 \%)$ & $3(13 \%)$ & \\
\hline $\begin{array}{l}\text { Individuals with a first } \\
\text { degree relative with } \\
\text { schizophrenia }\end{array}$ & 3 (19\%) & 3 (14\%) & $n^{3)}$ \\
\hline $\begin{array}{l}\text { Mean BPRS global score } \\
\text { at intake (SD) }\end{array}$ & $41.9(10.6)$ & $37.2(7.1)$ & $n s^{1)}$ \\
\hline $\begin{array}{l}\text { Mean SANS summary } \\
\text { score at intake (SD) }\end{array}$ & $9.5(5.4)$ & $6.8(4.4)$ & $n s^{1)}$ \\
\hline $\begin{array}{l}\text { Patients with } \\
\text { antipsychotics }\end{array}$ & 2 (13\%) & $2(9 \%)$ & $n^{2)}$ \\
\hline $\begin{array}{l}\text { Duration of Illness (mean } \\
\text { monthes, SD) }\end{array}$ & 42.6 (39.5) & $43.2(53.7)$ & $n s^{1)}$ \\
\hline
\end{tabular}

\footnotetext{
1) Student's t-tests

2) Fisher's exact test

${ }^{3)} \chi^{2}$-test
} 
Table 4 Whole brain and hippocampal volumes (raw and adjusted for whole brain volume)

\begin{tabular}{|c|c|c|c|c|c|c|c|c|c|c|}
\hline \multirow[t]{2}{*}{ Group } & \multirow{2}{*}{\multicolumn{2}{|c|}{ Whole Brain volume }} & \multicolumn{2}{|c|}{$\begin{array}{l}\text { Hippocampal } \\
\text { volume left }\end{array}$} & \multicolumn{2}{|c|}{$\begin{array}{l}\text { Hippocampal } \\
\text { volume right }\end{array}$} & \multicolumn{2}{|c|}{$\begin{array}{l}\text { Adjusted } \\
\text { Hippocampal } \\
\text { volume left }\end{array}$} & \multicolumn{2}{|c|}{$\begin{array}{l}\text { Adjusted } \\
\text { Hippocampal } \\
\text { volume right }\end{array}$} \\
\hline & & & (mm3) & (SD) & (SD) & (SD) & (mm3) & (SD) & (mm3) & (SD) \\
\hline $\begin{array}{l}\text { ARMS } \\
(\mathrm{n}=37)\end{array}$ & 1286747.8 & 113673.6 & 2915.8 & 311.8 & 3178.1 & 361.6 & 2980.1 & 374.6 & 3242.8 & 374.6 \\
\hline $\begin{array}{l}\text { - ARMS-T } \\
(\mathrm{n}=16)\end{array}$ & 1293439.1 & 103026.3 & 2956.3 & 251.4 & 3194.3 & 215.5 & 3003.7 & 311.8 & 3246.1 & 306.6 \\
\hline $\begin{array}{l}\text { - ARMS-NT } \\
(\mathrm{n}=21)\end{array}$ & 1281649.6 & 123430.6 & 2885.0 & 353.9 & 3165.8 & 447.4 & 2962.2 & 422.9 & 3240.3 & 426.6 \\
\hline $\begin{array}{l}\text { FEP } \\
(\mathrm{n}=23)\end{array}$ & 1307844.2 & 115519.9 & 2761.0 & 231.9 & 3139.6 & 249.4 & 2775.9 & 288.5 & 3159.7 & 344.4 \\
\hline $\begin{array}{l}\mathrm{HC} \\
(\mathrm{n}=22)\end{array}$ & 1307372.5 & 108978.1 & 2897.2 & 221.5 & 3196.9 & 235.8 & 2907.8 & 231.8 & 3210.7 & 271.0 \\
\hline
\end{tabular}

